\title{
Occurrence of selected aliphatic amines in source water of major cities in China
}

\author{
Haifeng Zhang ${ }^{1}$, Shuoyi Ren ${ }^{1,2}$, Jianwei $\mathrm{Yu}^{1}$, Min Yang ${ }^{1, *}$ \\ 1. State Key Laboratory of Environmental Aquatic Chemistry, Research Center for Eco-Environmental Sciences, Chinese Academy of Sciences, \\ Beijing 100085, China. E-mail: haifeng.hf@gmail.com \\ 2. College of Geosciences, China University of Petroleum, Beijing 102249, China
}

Received 10 February 2012; revised 27 March 2012; accepted 28 March 2012

\begin{abstract}
The formation of toxic nitrogenous disinfection byproducts (N-DBPs), such as nitrosamines, halonitromethanes and haloacetonitriles, from reactions between chlorine/chloramine and dissolved organic nitrogen in drinking water has caused great concern with regarding public health. This study revealed the occurrence of 17 aliphatic amines, some of which have been confirmed to be the precursors of N-DBPs, in source water across China. A sensitive method based on benzenesulfonyl chloride derivatization and liquid-liquid extraction followed by GC-MS analysis was established for the simultaneous analysis of the selected amines in aqueous samples. In total, 37 source water samples from the capital cities of 20 provinces were collected for the survey. Among the 17 amines, 14 were detected with an average frequency of detection of 36\%. The most relevant amines in terms of frequency and maximum concentrations detected were dimethylamine $(100 \%, 24.82 \mu \mathrm{g} / \mathrm{L})$, methylamine $(78 \%, 0.92 \mu \mathrm{g} / \mathrm{L})$, N-methylethylamine $(70 \%, 8.84 \mu \mathrm{g} / \mathrm{L})$, propylamine $(59 \%, 10.69 \mu \mathrm{g} / \mathrm{L})$, diethylamine $(54 \%, 3.76 \mu \mathrm{g} / \mathrm{L})$, N-methylbutylamine $(35 \%, 3.07 \mu \mathrm{g} / \mathrm{L})$, N-ethylpropylamine $(35 \%, 0.52 \mu \mathrm{g} / \mathrm{L})$, and piperidine $(32 \%, 2.35 \mu \mathrm{g} / \mathrm{L})$. This is the first large scale survey of the aliphatic amines occurrence in source water in the world. The wide presence of nitrosamine precursors like dimethylamine, $\mathrm{N}$-methylethylamine and diethylamine, and the precursors of haloacetonitriles and halonitromethanes like methylamine and propylamine suggests that better source water management is required to ensure the safety of drinking water.
\end{abstract}

Key words: primary amine; secondary amine; drinking water; disinfection byproducts

DOI: $10.1016 / \mathrm{S} 1001-0742(11) 61055-3$

\section{Introduction}

Aliphatic amines such as methylamine, dimethylamine, ethylamine, diethylamine, propylamine, morpholine, and piperidine, are important raw materials or intermediates used in chemical and pharmaceutical industries to produce dyes, synthetic polymers, rubbers, pesticides, cosmetics, medicines and corrosion inhibitor (Kirk-Othmer, 1978; Billiet, 1992). Some amines are produced in quantities of more than 200,000 tons per year in west Europe (Reemtsma and Jekel, 2006) and 80,000 tons per year in China (Yang, 2002). In addition to their industrial applications, some amines may occur as biodegradation products of proteins and amino acids, or other nitrogencontaining compounds. Besides hygienic problems due to their odorous smell, these compounds may be hazardous to human health as they are sensitizers and irritants to the skin, eyes, mucous membranes and respiratory tract, and some have even been considered as tumourinducing agents (Greim et al., 1998). Moreover, there is a growing concern that these compounds in source

\footnotetext{
* Corresponding author. E-mail: yangmin@ rcees.ac.cn
}

water may react with disinfectants during drinking water treatment process to form nitrogenous disinfection byproducts (N-DBPs) including haloacetonitriles, halonitromethanes (Joo and Mitch, 2007) and N-nitrosoamines (Mitch et al., 2003; Wang et al., 2011), which are considered to be potential human carcinogen compounds. Recently, several studies have shown that dimethylamine, diethylamine, morpholine and di- $n$-butylamine detected in source water would be important precursors of $\mathrm{N}$-nitorsodimethylamine (NDMA), N-nitrosodiethylamine (NDEA), N-nitrosomorpholine (NMOR) and N-nitrosodin-butylamine (NDBA), respectively, in drinking water (Mitch et al., 2003; Wang et al., 2011). Thus the occurrence data of these compounds is crucial for better control of the formation of the N-DBPs and improving drinking water quality.

Most previous studies have focused on the occurrence of amines in wastewater and receiving water bodies. Aliphatic amines were detected in wastewater influents and effluents from various wastewater treatment plants, with concentration levels ranging from several $\mu \mathrm{g} / \mathrm{L}$ to hundreds $\mu \mathrm{g} / \mathrm{L}$ (Pan et al., 1997; Sacher et al., 1997; Ábalos et al., 1999; Llop et al., 2010). At the same time, aliphatic amines of 
$\mathrm{ng} / \mathrm{L}$ to $\mu \mathrm{g} / \mathrm{L}$ level have been detected in some rivers (Sacher et al., 1997; Akyüz and Ata, 2006) and lakes (Cai et al., 2003) in Germany, Turkey, and China. However, to our knowledge, studies regarding the occurrence of aliphatic amines in source water are limited. Pietsch et al. (2001) studied the behavior of several aliphatic amines during the drinking water treatment process, and found that these compounds are difficult to be removed by conventional drinking water treatment process (i.e., coagulation, chlorination). Wang et al. (2011) studied the occurrence of eight aliphatic amines in several wastewater treatment plants in China, and suggested that diethylamine, morpholine and di- $n$-butylamine detected in source water would be important precursor for corresponding nitrosamines.

In this study, we optimized a method based on benzenesulfonyl chloride (BSC) derivatization and liquid-liquid extraction (LLE) followed by gas chromatography-mass spectrometry (GC-MS) analysis (Sacher et al., 1997) for the simultaneous analysis of 17 aliphatic amines in aqueous samples. Using this method, a nationwide survey was conducted to elucidate the occurrence of the selected amines in source water of the capital cities of 20 provinces across China. To our knowledge, this is the first comprehensive monitoring survey regarding the occurrence of the amines in source water in the world. Results of this study will provide useful information for source water management and optimization of drinking water treatment.

\section{Materials and methods}

\subsection{Reagents and solutions}

All amines were purchased in the highest purity available. Methylamine (MA), dimethylamine (DMA) and diethylamine (DEA) were used as hydrochlorides. MA, DMA, deuterated dimethylamine-d6 (DMA-d6), DEA, dipropylamine (DPA), dibutylamine (DBA), N-ethyl1-butylamine (EBA), N-methycylcohexylamine (MHA), pyrrolidine (PYR), piperidine (PIP), and Benzenesulfonyl chloride (BSC) were obtained from Sigma-Aldrich (USA). 1-Propylamine (PA), 1-butylamine (BA), 1hexylamine (HA), N-ethylmethylamine (MEA), N-methy1-propylamine (MPA), N-methyl-1-butylamine (MBA), N-ethylpropylamine (EPA), and morpholine (MOR) were purchased from Alfa Aesar (Tianjin, China). Dichloromethane for organic residue analysis was purchased from J.T. Baker (USA). Guaranteed reagent grade hydrochloric acid was provided by Merck (Darmstadt, Germany). All other chemicals, such as sodium sulfate, sodium hydroxide pellets and sodium carbonate were of analytical grade. Ultrapure water $(18.2 \mathrm{M} \Omega \cdot \mathrm{cm})$ was prepared using a Milli-Q purification system (Millipore Inc., USA).

Stock standard of all amines $(1 \mathrm{mg} / \mathrm{mL})$ was prepared in methanol-water mixture $(50: 50, \mathrm{~V} / \mathrm{V})$ and stored at $4{ }^{\circ} \mathrm{C}$ in the dark. Working solutions were prepared by sequential dilution of each standard solution with ultrapure water.

\subsection{Sampling}

Thirty-seven source water samples were taken from the capital cities of 20 provinces across China, as shown in Fig. 1. Water samples were collected in $4 \mathrm{~L}$ amber glass bottles from various locations, and delivered under cooled conditions ( $4^{\circ} \mathrm{C}$ in cooling boxes) within $48 \mathrm{hr}$ to the lab. Before the analysis, water samples were filtered through $0.45 \mu \mathrm{m}$ Supor membrane filters (Pall Co., Ann Arbor, USA).

\subsection{Sample preparation}

First, $20 \mu \mathrm{L}$ of an aqueous solution of $50 \mathrm{mg} / \mathrm{L}$ dimethylamine-d6 as internal standard were added to 200 $\mathrm{mL}$ water sample in a $250 \mathrm{~mL}$ round bottomed flask. The mixture was basified with $8 \mathrm{~mL}$ of $10 \mathrm{~mol} / \mathrm{L}$ aqueous sodium hydroxide solution and $2 \mathrm{~mL} \mathrm{BSC}$ were added. The flask was closed and agitated for $30 \mathrm{~min}$ at room temperature. Then another $10 \mathrm{~mL}$ of $10 \mathrm{~mol} / \mathrm{L}$ sodium hydroxide solution was added and the mixture was agitated again for $30 \mathrm{~min}$ at $80^{\circ} \mathrm{C}$ to hydrolyze residual derivatization reagent. Subsequently the solution was cooled down with ice water under steady cooling and acidified with $18.5 \%$ aqueous solution of hydrochloric acid to $\mathrm{pH} 5.5$. The mixture was extracted twice with $25 \mathrm{~mL}$ dichloromethane. Whereas the aqueous solution was discarded, the organic phase was washed once with $15 \mathrm{~mL} 0.05 \mathrm{~mol} / \mathrm{L}$ aqueous sodium carbonate solution and dried with sodium sulfate. The solvent was evaporated to $100 \mu \mathrm{L}$ and $1 \mu \mathrm{L}$ was injected into the gas chromatograph (Sacher et al., 1997). All samples were measured in duplicate.

\subsection{GC-MS analysis}

An Agilent 6890N gas chromatograph (Agilent, USA) equipped with a split/splitless injector connected to an Agilent 5975C mass detector using an ionization voltage of 70 $\mathrm{eV}$ was used for the analysis of the amines. GC column was a DB-5MS (30 $\mathrm{m} \times 250 \mu \mathrm{m}$ i.d., $0.25 \mu \mathrm{m}$ film thickness)

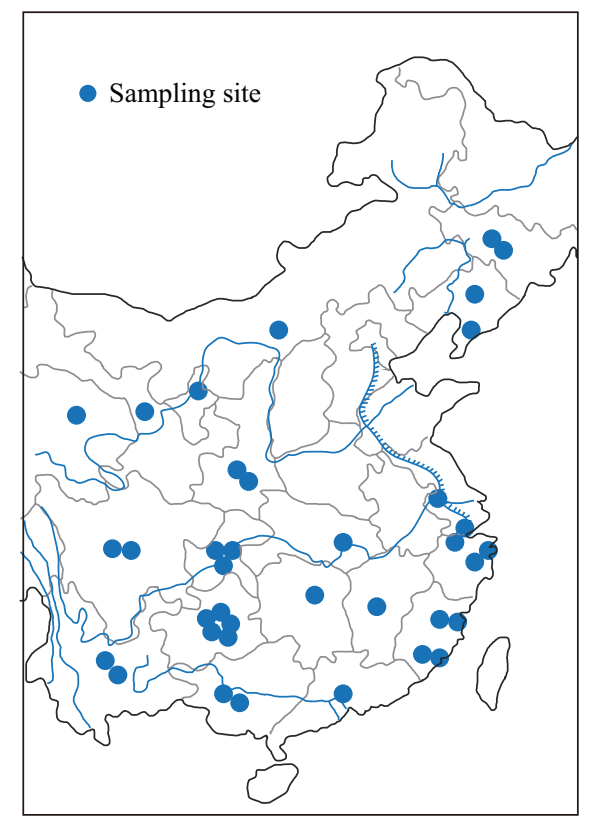

Fig. 1 Sampling sites. 
column. Helium (99.999\%) was employed as the carrier gas with an inlet pressure of 17.57 psi corresponding to a flow rate of $1.5 \mathrm{~mL} / \mathrm{min}$. The oven temperature was initially at $120^{\circ} \mathrm{C}$ for $3 \mathrm{~min}$; programmed to $220^{\circ} \mathrm{C}$ at $5^{\circ} \mathrm{C} / \mathrm{min}$, then programmed to $290^{\circ} \mathrm{C}$ at $10^{\circ} \mathrm{C} / \mathrm{min}$ and held at $290^{\circ} \mathrm{C}$ for $5 \mathrm{~min}$. The injector and detector temperatures were maintained at $290^{\circ} \mathrm{C}$ and samples were introduced in splitless injection mode. The electron impact (EI) source temperature was kept at $230^{\circ} \mathrm{C}$.

\section{Results and discussion}

\subsection{GC-MS analysis}

In this study, amine analytes were derivatized with BSC and their BSC derivatives were analysed by GC-MS. Figure 2 shows the GC-MS chromatogram of a derivatized standard mixture of $1 \mathrm{ng}$ of each compound. With the optimized temperature program, separation of individual BSC derivatives was successfully achieved. The masses of the characteristic fragments using MS detection with EI are summarized in Table 1.

\subsection{Method validation}

Limits of detection (LODs, $S / N=3$ ), limits of quantification (LOQs, $S / N=9$ ) and reproducibilities of the method were determined using spiked ultrapure water, as shown in Table 2. Quantification was performed using the internal standard method. Seven-point calibration curves were constructed for analytes across a range of concentrations from $100 \mathrm{ng} / \mathrm{L}$ to $10 \mu \mathrm{g} / \mathrm{L}$. Analyte calibrations were linear from the detection limits past the upper range of calibration concentrations $\left(R^{2}>0.99\right)$ for all target amines.

To identify possible contamination, blank controls were analyzed. Blank values for the analytes were under the LODs.
Table 1 Main mass fragments of the 17 amines

\begin{tabular}{|c|c|}
\hline Compound & Fragment masses $m / z$ \\
\hline MA & $\underline{77}, 106, \underline{141}, \mathbf{1 7 1}$ \\
\hline PA & $\underline{77}, 78,1 \overline{41}, \mathbf{1 7 0}, \underline{199}$ \\
\hline $\mathrm{BA}$ & $\overline{77}, \underline{141}, 158,170, \overline{21} 3$ \\
\hline HA & $\overline{77}, \overline{100}, \underline{141}, 158, \mathbf{1 7 0}, \underline{241}$ \\
\hline DMA & $\overline{77}, \overline{78}, 1 \overline{20}, \underline{141}, \mathbf{1 8 5}$ \\
\hline DEA & $\overline{77}, 141, \mathbf{1 9 8 , 2 1 3}$ \\
\hline DPA & $\overline{77}, \underline{141}, 170,212$ \\
\hline DBA & $\overline{77}, \overline{141}, 170,184,226$ \\
\hline MEA & $\overline{77}, \overline{141}, 184$ \\
\hline MPA & $\overline{77}, \overline{84}, 125, \underline{141}, \mathbf{1 8 4}, \underline{213}$ \\
\hline MBA & 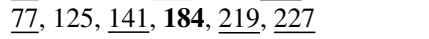 \\
\hline MHA & $\overline{77}, 112, \overline{125}, 133, \underline{141}, \overline{184}, \underline{\mathbf{2 1 0}}, \underline{253}$ \\
\hline EPA & $\underline{77}, 84, \underline{141}, \mathbf{1 9 8}, \underline{212}, \underline{227}$ \\
\hline EBA & $\overline{77}, 125, \overline{141} 1,198, \overline{22} 6, \overline{24} 1$ \\
\hline PYR & $\overline{70}, 77,1 \overline{41,210,211}$ \\
\hline MOR & $77,86,141,184,196,227$ \\
\hline PIP & $77,84, \overline{141}, \overline{224}, \mathbf{2 2 5}$ \\
\hline
\end{tabular}

Underlined: mass fragments used for SIM, bold: mass fragments chosen for quantification.

\subsection{Overview of environmental samples}

The method developed was applied to analyze the target amines in source water samples in a survey in 2010. Figure 3 shows an exemplary GC-MS chromatogram of one river-type source water sample. A summary of the analytical results for the target amines in 37 source water samples is given in Table 3. The overall frequency of detection for the amines (above the LOD) is shown by the percentile frequency of detection for the compounds. Among the 17 amines, 14 were detected with an average frequency of detection of $36 \%$. The most frequently detected amines were DMA (freq 100\%), followed by MA (freq $78 \%$ ), MEA (freq 70\%) and PA (freq 59\%). DMA, MA, MEA and PA are important industrial intermediates with significant usage in the production of pharmaceutical products, pesticides, dyes, and rubber (Reemtsma and Jekel, 2006; Sacher et al., 1997). The high detection frequency

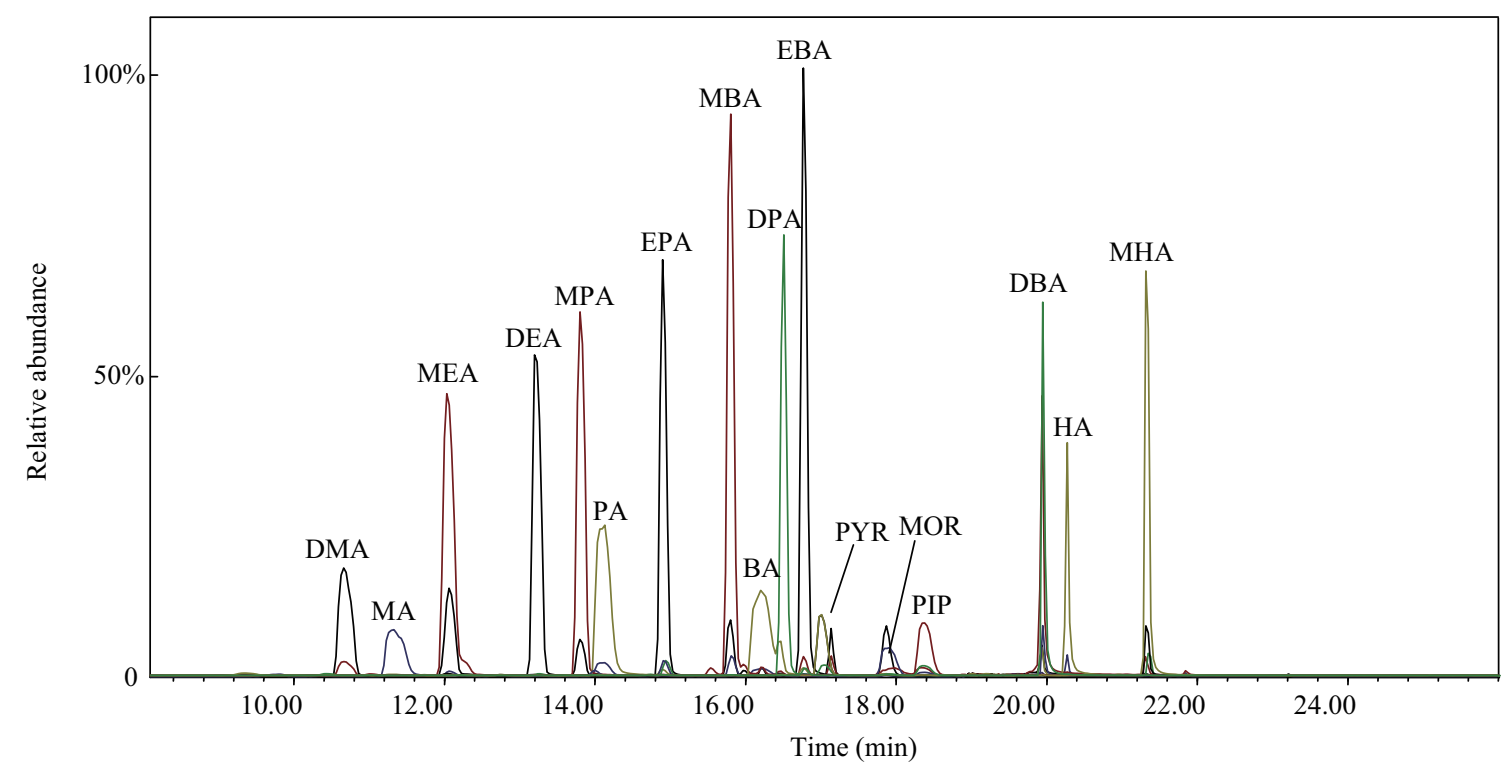

Fig. 2 Reconstructed selected ion monitoring (SIM) chromatogram of BSC derivatives of the standard amine mixture: dimethylamine (DMA); methylamine (MA); N-ethylmethylamine (MEA); diethylamine (DEA); N-methyl-1-propylamine (MPA); 1-propylamine (PA); N-ethylpropylamine (EPA); N-methyl-1-butylamine (MBA); 1-butylamine (BA); dipropylamine (DPA); N-ethyl-1-butylamine (EBA); pyrrolidine (PYR); morpholine (MOR); piperidine (PIP); dibutylamine (DBA); 1-hexylamine (HA); N-methylcyclohexylamine (MHA). 


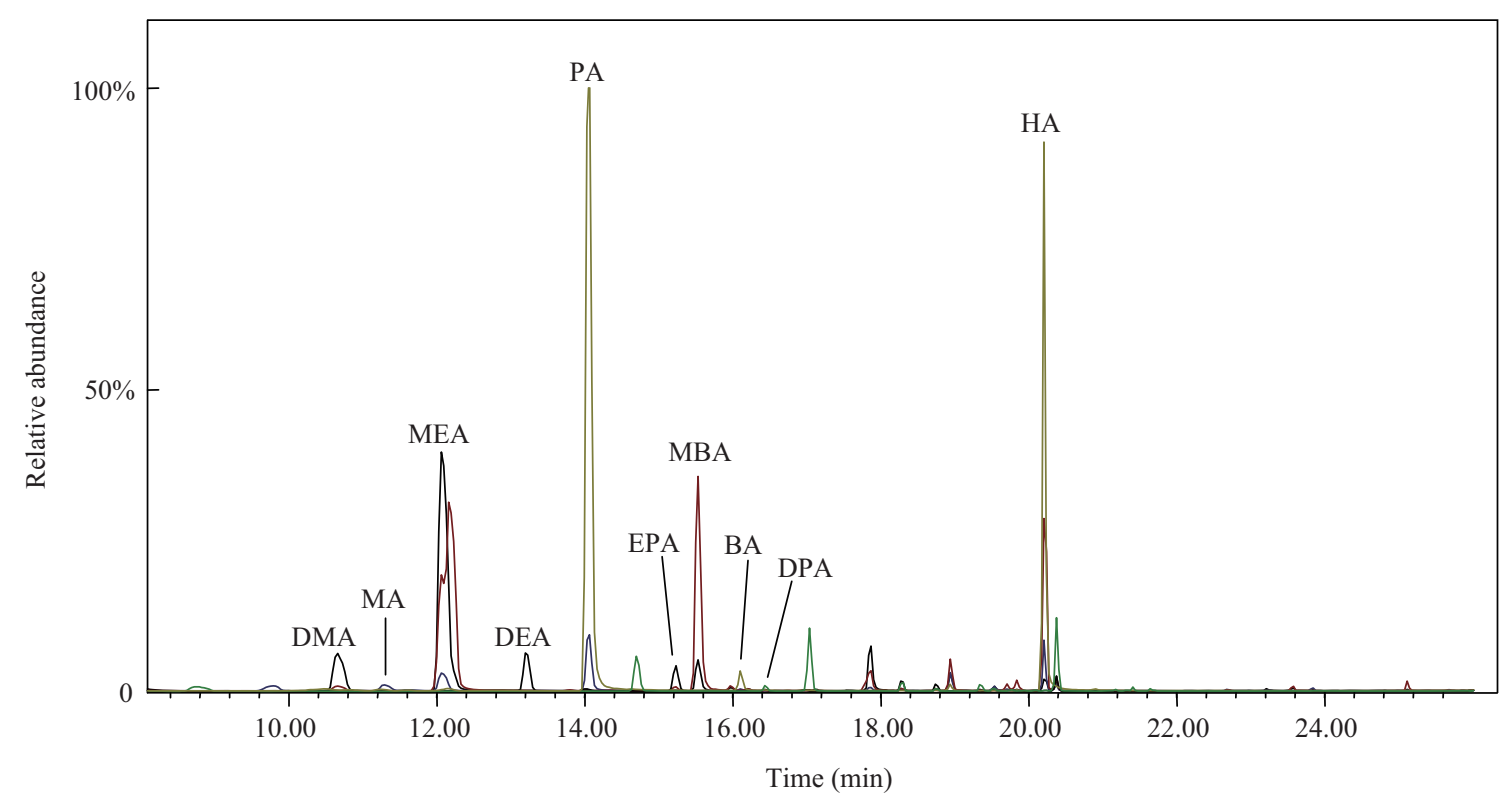

Fig. 3 Reconstructed SIM chromatogram of BSC derivatives of amines detected in one of the source water. dimethylamine (DMA); methylamine (MA); N-ethylmethylamine (MEA); diethylamine (DEA); 1-propylamine (PA); N-ethylpropylamine (EPA); N-methyl-1-butylamine (MBA); 1-butylamine (BA); dipropylamine (DPA); 1-hexylamine (HA).

Table 2 Performance of the method

\begin{tabular}{lllll}
\hline Compound & $\begin{array}{l}\text { LOD } \\
(\mathrm{ng} / \mathrm{L})\end{array}$ & $\begin{array}{l}\text { LOQ } \\
(\mathrm{ng} / \mathrm{L})\end{array}$ & $R^{2}$ & $\begin{array}{l}\text { Reproducibility } \\
(\% \mathrm{RSD})\end{array}$ \\
\hline MA & 3.5 & 10.6 & 0.999 & 4.81 \\
PA & 0.8 & 2.5 & 0.999 & 2.50 \\
BA & 9.1 & 27.3 & 0.999 & 3.11 \\
HA & 2.7 & 8.2 & 0.999 & 2.28 \\
DMA & 4.7 & 14.2 & 0.999 & 2.32 \\
DEA & 2.4 & 7.3 & 0.999 & 5.37 \\
DPA & 1.5 & 4.5 & 0.999 & 3.34 \\
DBA & 1.6 & 4.7 & 0.999 & 3.26 \\
MEA & 0.6 & 1.8 & 0.999 & 4.28 \\
MPA & 33.1 & 99.3 & 0.996 & 12.49 \\
MBA & 25.0 & 75.0 & 0.997 & 17.41 \\
MHA & 6.8 & 20.5 & 0.993 & 3.20 \\
EPA & 1.6 & 4.9 & 0.999 & 2.74 \\
EBA & 0.9 & 2.8 & 0.993 & 3.93 \\
PYR & 32.1 & 96.3 & 0.999 & 2.55 \\
MOR & 10.3 & 31.0 & 0.999 & 4.94 \\
PIP & 65.4 & 196.2 & 0.999 & 3.61 \\
\hline LOD: & & 19.9 &
\end{tabular}

LOD: limit of detection $(S / N=3)$; LOQ: limit of quantification $(S / N=$ 9); RSD: relative standard deviation.

of these amines suggested that degradation of widely used anthropogenic precursors such as pesticides, dyes, drugs may be important sources for DMA, MA, MEA, and PA in source water. The amines which were detected at a low overall frequency were DBA (freq 24\%), HA (freq 19\%), MOR (freq 11\%), PYR (freq $8 \%$ ), BA (freq 8\%) and EBA (freq 5\%), suggesting that industrial production could be the primary source for these amines. EBA. MPA, DPA and MHA were also analysed, but were never detected above the LODs. This is in accordance with the fact that the production and usage of MPA, DPA, MHA are relative small (Reemtsma and Jekel, 2006).

Table 3 also shows the maximum and medium concentration levels for the compounds studied. The single amines with the highest maximum concentrations were DMA $(24.82 \mu \mathrm{g} / \mathrm{L})$, PA $(10.69 \mu \mathrm{g} / \mathrm{L})$, MEA $(8.84 \mu \mathrm{g} / \mathrm{L})$ and HA $(7.74 \mu \mathrm{g} / \mathrm{L})$. The highest median concentrations
Table 3 Summary of analytical results for the 17 amines in source waters

\begin{tabular}{llllll}
\hline Compound & $\begin{array}{l}\text { Freq } \\
(\%)\end{array}$ & $\begin{array}{l}\text { Max } \\
(\mu \mathrm{g} / \mathrm{L})\end{array}$ & $\begin{array}{l}\text { Med } \\
(\mu \mathrm{g} / \mathrm{L})\end{array}$ & Per90 & Per10 \\
\hline MA & 78 & 0.92 & 0.22 & 0.65 & 0.12 \\
PA & 59 & 10.69 & 1.47 & 7.66 & 0.35 \\
BA & 8 & 0.25 & 0.21 & 0.24 & 0.14 \\
HA & 19 & 7.74 & 0.57 & 4.53 & 0.23 \\
DMA & 100 & 24.82 & 0.56 & 4.03 & 0.16 \\
DEA & 54 & 3.76 & 0.58 & 1.68 & 0.15 \\
DPA & 0 & n.a. & n.a. & n.a. & n.a. \\
DBA & 24 & 0.85 & 0.20 & 0.52 & 0.12 \\
MEA & 70 & 8.84 & 1.78 & 7.13 & 0.36 \\
MPA & 0 & n.a. & n.a. & n.a. & n.a. \\
MBA & 35 & 3.07 & 1.89 & 2.44 & 0.50 \\
MHA & 0 & n.a. & n.a. & n.a. & n.a. \\
EPA & 35 & 0.52 & 0.32 & 0.39 & 0.13 \\
EBA & 5 & 0.22 & 0.17 & 0.21 & 0.13 \\
PYR & 8 & 0.39 & 0.15 & 0.34 & 0.13 \\
MOR & 11 & 0.93 & 0.51 & 0.90 & 0.14 \\
PIP & 32 & 2.35 & 1.44 & 1.88 & 0.68 \\
\hline
\end{tabular}

Freq: frequency of detection; Max: maximum concentration; Med: medium concentration; Per90: percentile 90\%; Per10: percentile 10\%; n.a.: not applicable.

were measured for MBA $(1.89 \mu \mathrm{g} / \mathrm{L})$, MEA $(1.78 \mu \mathrm{g} / \mathrm{L})$, PA $(1.47 \mu \mathrm{g} / \mathrm{L})$ and PIP $(1.44 \mu \mathrm{g} / \mathrm{L})$, showing the relevance of these compounds.

\subsection{Environmental implication}

As mentioned above, aliphatic amines are important precursors of N-DBPs. Considering the molar yields of $\mathrm{N}-\mathrm{DBPs}(0.1 \%-29.0 \%$ for primary amines and 1\%-5\% for secondary amines) (Joo and Mitch, 2007; Wang et al., 2011) and current recommend levels for the corresponding DBPs (for example $10 \mathrm{ng} / \mathrm{L}$ for NDMA) (Richardson et al., 2007), a warning level of $1 \mu \mathrm{g} / \mathrm{L}$ was set in this study. Above the level, the amine will make a remarkable contribution to the overall pool of DBPs. Among the amines detected above the $1 \mu \mathrm{g} / \mathrm{L}$, PA was the most relevant 
primary amine found in this study, with a frequency of detection of $59 \%$ and the maximum concentration of 10.69 $\mu \mathrm{g} / \mathrm{L}$. PA was also detected in surface water in other studies (Pietsch et al., 1996; Lloret et al., 2002; Weiss and Angerer, 2002; Cai et al., 2003; Yazdi and Es'haghi, 2005) and has been proven as a precursor of propionitrile, propionaldehyde, and dichloronitropropane (Joo and Mitch, 2007). The most relevant secondary amine for source water found in this study was DMA, which was detected in all of the samples with a maximum concentration of $24.82 \mu \mathrm{g} / \mathrm{L}$. In comparison to concentrations of DMA observed in previous studies $(10 \mathrm{ng} / \mathrm{L}-3 \mu \mathrm{g} / \mathrm{L})$ (Sacher et al., 1997; Akyüz and Ata, 2006), the concentrations of DMA observed in source water samples in this study were relatively high. This may cause a remarkable risk of NDMA formation during disinfection of drinking water, because DMA has been proven as an important NDMA precursor during drinking water disinfection (Wang et al., 2011). Other relevant secondary amines detected were MEA (freq 70\%, max conc. $8.84 \mu \mathrm{g} / \mathrm{L}$ ), DEA (freq $54 \%$, max conc. $3.76 \mu \mathrm{g} / \mathrm{L}$ ), MBA (freq $35 \%$, max conc. 3.07 $\mu \mathrm{g} / \mathrm{L}$ ) and PIP (freq 32\%, max conc. $2.35 \mu \mathrm{g} / \mathrm{L}$ ). MEA, DEA and PIP have also been proven to serve as precursors for corresponding nitrosamines during water disinfection (Joo and Mitch, 2007). Although, up to now, occurrence of $\mathrm{N}$-nitrosomethylbutylamine in drinking water has not been reported, considering the similar structure of MBA to other secondary amines and occurrence of MBA in source water at a relatively high concentration, further study is needed to investigate if $\mathrm{N}$-nitrosomethylbutylamine form during disinfection of MBA contaminated source water.

\section{Conclusions}

In this study, source water samples from 37 locations across China were analysed for the selected aliphatic amines. The most relevant amines in terms of frequency of detection and maximum concentrations detected were DMA $(100 \%, 24.82 \mu \mathrm{g} / \mathrm{L})$, MA $(78 \%, 0.92 \mu \mathrm{g} / \mathrm{L})$, MEA (70\%, $8.84 \mu \mathrm{g} / \mathrm{L})$, PA $(59 \%, 10.69 \mu \mathrm{g} / \mathrm{L})$, DEA (54\%, 3.76 $\mu \mathrm{g} / \mathrm{L}), \operatorname{MBA}(35 \%, 3.07 \mu \mathrm{g} / \mathrm{L}), \operatorname{EPA}(35 \%, 0.52 \mu \mathrm{g} / \mathrm{L})$ and PIP $(32 \%, 2.35 \mu \mathrm{g} / \mathrm{L})$. Compared to other studies, relatively high concentrations of some amines were observed in this study, indicating possible heavy contamination of some water bodies. The results of this monitoring survey are a valuable help for identifying possible relevant amine pollutants in source water. Although, currently, no threshold limit values exist for amine pollutants in source water, such limit values are necessary to be established for improving drinking water quality and protecting human health.

\section{Acknowledgments}

This work was supported by the National Natural Science Foundation of China (No. 21077118) and the National Special Funding Project for Water Pollution Control and Management of China (No. 2009ZX07419-001). The authors would like to express their gratitude towards the water monitoring stations in related cities for their kind help in sampling.

\section{References}

Ábalos M, Bayona J M, Ventura F, 1999. Development of a solid-phase microextraction GC-NPD procedure for the determination of free volatile amines in wastewater and sewage-polluted waters. Analytical Chemistry, 71(16): 3531-3537.

Akyüz M, Ata Ş 2006. Simultaneous determination of aliphatic and aromatic amines in water and sediment samples by ionpair extraction and gas chromatography-mass spectrometry. Journal of Chromatography A, 1129(1): 88-94.

Billiet H A H, 1992. Chapter 25 Amines from environmental sources. Journal of Chromatography Library, 51(Part B): B583-B595.

Cai L S, Zhao Y Y, Gong S L, Dong L, Wu C Y, 2003. Use of a novel sol-gel dibenxo-18-crown-6 solid-phase microextraction fiber and a new derivatizing reagent for determination of aliphatic amines in lake water and human urine. Chromatographia, 58(9-10): 615-621.

Greim H, Bury D, Klimisch H J, Oeben-Negele M, ZieglerSkylakakis K, 1998. Toxicity of aliphatic amines: Structureactivity relationship. Chemosphere, 36(2): 271-295.

Joo S H, Mitch W A, 2007. Nitrile, aldehyde, and halonitroalkane formation during chlorination/chloramination of primary amines. Environmental Science $\mathcal{E}$ Technology, 41(4): 12881296.

Kirk-Othmer, 1978. Kirk-Othmer Encyclopedia of Chemical Technology. Wiley-Interscience, New York.

Llop A, Pocurull E, Borrull F, 2010. Automated determination of aliphatic primary amines in wastewater by simultaneous derivatization and headspace solid-phase microextraction followed by gas chromatography-tandem mass spectrometry. Journal of Chromatography A, 1217(4): 575-581.

Lloret S M, Legua C M, Falco P C, 2002. Preconcentration and dansylation of aliphatic amines using $\mathrm{C}_{18}$ solid-phase packings: Application to the screening analysis in environmental water samples. Journal of Chromatography A, 978(1-2): $59-69$.

Mitch W A, Sharp J O, Trussell R R, Valentine R L, AlvarezCohen L, Sedlak D L, 2003. $N$-nitrosodimethylamine (NDMA) as a drinking water contaminant: A review. Environmental Engineering Science, 20(5): 389-404.

Pan L, Chong J M, Pawliszyn J, 1997. Determination of amines in air and water using derivatization combined with solid-phase microextraction. Journal of Chromatography A, 773(1-2): 249-260.

Pietsch J, Hampel S, Schmidt W, Brauch H J, Worch E, 1996. Determination of aliphatic and alicyclic amines in water by gas and liquid chromatography after derivatization by chloroformates. Fresenius Journal of Analytical Chemistry, 355(2): 164-173.

Pietsch J, Sacher F, Schmidt W, Brauch H J, 2001. Polar nitrogen compounds and their behaviour in the drinking water treatment process. Water Research, 35(15): 3537-3544.

Reemtsma T, Jekel M, 2006. Chapter 8 Amines. In: Organic Pollutants in the Water Cycle. Wiley, Weiheim. 181-210.

Richardson S D, Plewa M J, Wagner E D, Schoeny R, Demarini D M, 2007. Occurrence, genotoxicity, and carcinogenicity of regulated and emerging disinfection by-products in drinking water: A review and roadmap for research. Mutation Research-Reviews in Mutation Research, 636(1-3): 178- 
242.

Sacher F, Lenz S, Brauch H J, 1997. Analysis of primary and secondary aliphatic amines in waste water and surface water by gas chromatography-mass spectrometry after derivatization with 2,4-dinitrofluorobenzene or benzenesulfonyl chloride. Journal of Chromatography A, 764(1): 85-93.

Wang W F, Ren S Y, Zhang H F, Yu J W, An W, Hu J Y et al., 2011. Occurrence of nine nitrosamines and secondary amines in source water and drinking water: potential of secondary amines as nitrosamine precursors. Water Research, 45(16): 4930-4938.
Weiss T, Angerer J, 2002. Simultaneous determination of various aromatic amines and metabolites of aromatic nitro compounds in urine for low level exposure using gas chromatography-mass spectrometry. Journal of Chromatography B, 778(1-2): 179-192.

Yang W G, 2002. Production trend of dimethylamine. China Chemicals, 2002(1): 26.

Yazdi A S, Es'haghi Z, 2005. Liquid-liquid-liquid phase microextraction of aromatic amines in water using crown ethers by high-performance liquid chromatography with monolithic column. Talanta, 66(3): 664-669. 